\title{
For Standards of Surveillance Camera Control Systems in The United Arab Emirates Public Agencies
}

\author{
Abdulla Salem Al Ashkhari \\ Universiti Teknikal Malaysia Melaka (UTeM)
}

\begin{abstract}
In this paper, the problems of standardizing procedures and applications for monitoring cameras system control procedures in all vital complexes of the UAE government to address the enormity of evaluating the standardization of monitoring cameras system control procedures in all UAE government vital complexes subject to performance systems in line with international standards. In essence, the report used previous literature review to drive home its point about the region's precarious state of disaster and the need for mitigation measures. The study concludes by proposing a conceptual model for the development of best practices for cameras monitoring system control procedures in all critical UAE government complexes.
\end{abstract}

Keywords : Standards, Surveillance, Camera, Control Systems

\section{INTRODUCTION}

In last 10 years the United Arab Emirates tends to increase the deployed of surveillance camera which helping in assuring Security and safety procedures and tracking any criminal events everywhere and anytime. In Dubai only there are about 30,000 and about 3000 of them located only in airport (Hilotin, 2013).Also Abu Dhabi interested in deployed the surveillance camera which expressed in the Safety and Security Planning Manual (SSPM) in its 2030 vision (Vision 2030, 2017). There is legislative framework regarding the surveillance camera which regulated by law,a law no 24 of 2008 have obligated the public and private sectors in Dubai, especially the commercial zones to installed a surveillance camera and it provides guidelines for service providers and users in how and when the surveillance camera will be setting(Taylor-Wessing, 2014).For expanding the domain of security and safety to include the residential units and towers, another new law No.10 of 2014 was issued to amend the provision of pervious one no 24 of 2008, which permit owner of those building to install a surveillance camera through allowance period of 3 months (Siassios, and Tamimi, 2014). The increasing demand for buying surveillance camera, in the same time there is a unified law covers the standard of surveillance camera, resulted in a large market for selling unregulated and substandard surveillance camera system equipment. Although, Telecommunications Regulatory Authority (TRA), is the only agency which give the approval for any telephone, mobile or smart phone to be sold in the UAE market, there is no approval procedures in the term of surveillance camera (Hilotin, 2013).

There are many factors should be considered when installed the surveillance camera system, such as the proper place of camera, lenses type, resolution of the cameras, storage space, and codecs programs, to be more assistance for operators and law enforcement agencies. These factors are not separated from one another but should be complementary to each other according to the purpose of the surveillance camera. For instance, when adding additional camera to an existing system, need more changes in the storage spaces, and also the average of recorded images of each camera (APTA, 2011).The most obstacles that the user face in the surveillance camera system is the technical problems that is reflect the importance of properly installing of these devices to be effective for its purpose, in addition to the lack of standard and clear instruction, especially with rapid changes occurring in the realm of surveillance camera technology (Honovich 2008).Furthermore, surveillance cameras can bring some problems, such as coverage a limited area, malfunction in design system and poor tape quality, incorrect use, lack of maintenance and the absence of responsibility by the users. These technical problems are impeding the effectiveness of surveillance cameras systems, and many of such problems still not addressed or even recognized (Carli, 2008).

The standard gives recommendations for surveillance camera installed for use in security and specifies minimum requirements. It specifies the minimum performance and functional requirements which should be agreed by the customer and installer as well as law enforcement agencies where needed(Frois, 2013). The standard also applies where the system shares detection, triggering, interconnection, control, communication or power supply with another security application such as an intruder alarm system. It does not include requirements for design, planning, installation, testing, operation or maintenance (Qureshi, 2013). 
The standard also excludes installation of remotely monitored detector activated camera surveillance. In particular, this standard highlight some of the key features that any good surveillance camera system should provide, such as effective image export capability and an easily re-playable data format, both of which are critical if the pictures may be used as evidence in an investigation(Frois, 2013 and Cumming, 2015). The only way to protect users' investments and future-proof their surveillance camera systems is to truly embrace open standards, which enhance the innovation and improvement of product quality, also provide flexibility in finding solutions for a wide range of different cameras. Companies that want to survive the consolidation trend and achieve sustainable, profitable growth will need to build standards-based video integration platforms (Lim et al., 2016). Free and uninterrupted access to the underlying code for camera drivers is a real strength of the true open standards approach. In-house or third-party developers can address bugs and issues immediately without needing to rely on a vendor, whose priorities and resources may not always align with users.

The UAE's National Electronic Security Authority (NESA) is tasked with developing and monitoring the UAE Information Assurance Standards (IAS). The IAS come under the National Information Assurance Framework (NIAF), which itself is part of the Critical Information Infrastructure Protection (CIIP) Policy. The surveillance cameras protocol in extremely difficult especially that the human factor is reinforcing the diversion of some of the scenes and important information to other destinations is a national, affecting the national security Emirates Additional. the large number of monitoring bodies in the UAE, it promotes randomization, so the study made a comparison between NESA and international standards to reach the best results.

Surveillance camera operations are spreading across the world in the private and public sectors. Systems are used to prevent crime, assist in investigating criminal offenses, reduce the need for human resources and increase homeland security protection grids. Legal and professional standards should be implemented to solidify the public's faith in the ability of government to protect civil liberties as technology evolves(Cumming and Johan, 2015; and Lim et al., 2016). Standards have played virtually no role in digital video security until very recently, but that is quickly changing. At widely varying paces, enterprises are shifting from proprietary, analog video systems to open digital solutions and with that market shift, they are creating an intensified drive for standards. This shift to digital coupled with the introduction of video content analysis or video analytics promises to extend the reach of video beyond security and into the enterprise to provide a rich source of data for business optimization(Qureshi, 2013).

Standards promote interoperability and reduce integration cost(Kim and Park, 2016). Unfortunately, the surveillance camera industry has been slow to adopt standards. With the introduction of feature-rich digital surveillance cameras and encoders, which offer higher resolutions and embedded analytic capabilities, users have benefited from an increased choice of devices and capabilities. A lack of standards, however, has kept some of these devices out of reach. In addition to limiting customer choice, this standards deficiency increases integration costs for solution providers and manufacturers(Webster, 2002). More importantly, it results in opportunity costs that lead to reduced innovation as surveillance camera vendors waste research and development dollars on integration activity instead of focusing efforts on new functionality. The good news is that the video security industry is finally responding and a few attempts at standardization are underway. One such effort is the Physical Security Interoperability Alliance (PSIA), a group of leading physical security industry and IT manufacturers, system integrators and distributors that has come together to promote the interoperability of security devices, and is currently focused on several initiatives.

Another point we should consider, when the state intend to install a new surveillance camera systems, especially for public agencies, there are some important considerations should be taken from city administrators and law enforcement agencies for facing both financial and social challenges. Therefore, good planning, integration and innovation will support and help the law enforcement agencies to avoid these challenges for successful implementation of public surveillance camera control system. Also, Surveillance systems in public places may be lead to a secondary impact, such increasing lawful users' perceptions of safety and thus their presence in public areas, which in turn will increase and improve the trusteeship of police-community partnerships, and reduce crime (La Vigne et al., 2011). All what mentioned above circulate around the lack of unified standards which importantly required for a good implementation of surveillance systems, therefore, this article will focus on the standards requirements for adding, configuring and managing digital surveillance cameras and encoders, hereafter referred to simply as a digital media device or digital camera (Simonato, 2014 and Piza, 2016). 


\section{Research Methodology}

The method of current study is designed based on the research's objectives, and to answer the research questions. As the main objective is to set a framework for standards of surveillance camera control systems, and there is a little studies in this area, especially in the United Arab Emirates, and there is a need to more understanding of this systems and explore some facts related to this topic. Therefore a qualitative - exploratory research method will employed in this study. The exploratory research is recommended when the objective is to explore an area where little is known, and to develop, refine and test measurement tools and procedures (Kumar, 2011), or to better comprehend the nature of the problem since very few studies might have been conducted in that area. Also, exploratory studies are necessary when some facts are known but more information is needed for developing a viable theoretical framework, especially when knowledge is scant, and a deeper understanding is sought (Sekaran, 2010).

Qualitative research method is a holistic approach that depend on discovery. The qualitative research considered as an effective model which investigate the study problem from the participant's perspective that has actual experiences, and that enable the researcher to reach in-depth details of the particular problem which occur in the natural setting (Williams, C. 2007; Creswell, 2014; Rahi, 2017). The qualitative research, reflecting the 'exploratory' philosophical base of the research approach, and in this case the study population and the research problem should be flexible to ensure the freedom necessary to get varied and in-depth data if a situation changed (Kumar, 2011). Whereas, quantitative method is focus in gathering data from large sample and the analysis output is to describe the data not to interpret it (Rahi, 2017). The population sample will be the vital public agencies in United Arab Emirates. The contact person for each of the noted UAE agencies will have to be agreed to submit to a survey. There are two methods of collecting data, questionnaire and interview. Questionnaire is considered as an objective method that collect data from large population, (Harris et al., 2010). Interviews is a suitable methods when a researcher want to gain more and in depth information, but consuming time (Alshenqeeti, 2014). The questionnaire will be suitable for this study where there are a direct questions, clear in the meaning, and oriented for specific respondents. In addition it is rapid and easily method in case of surveying conducting to cover a wide far geographical regions (Paradiset al., 2016). The target population will be the persons who working in public agencies and responsible for the security, control and monitor of surveillance camera system. In other word the individuals whom deal directly with the surveillance camera systems. In the first stage (online survey), the sample comprises all organizations of UAE such as The UAE's National Electronic Security Authority (NESA), Information Assurance Standards (IAS), National Information Assurance Framework (NIAF) and Critical Information Infrastructure Protection (CIIP) Policy.Along with invitation participation to organizations to decide if they are willing to participate in the research, the questionnaire will be the persons who working in public agencies and responsible for the security, control and monitor of surveillance camera system and citizen of UAEto obtain their opinions in current system, the questionnaire will be attached to ask them for continuing the following interview protocol. The sample will be asked to leave contact information (email or telephone number) for further study if they agree to. In the second stage (face to face interview), an interview protocol will be used to collect data of organizations to see how they evaluate the kind of material they are implementation ofsurveillance camera system, how this system can be understand to gather information about the integration of surveillance in UAE, to find out how they implement the use of current system in their offices to find out if they have ever used ethical standards. The interview protocol will be developed using the responses from the trends of online survey questionnaire

\section{Research Gaps}

While the available empirical research seem to have established some correlation between the implementation of public surveillance systems and crime reduction, it was not clear on what standard requirements on public surveillance systems should adopt. Given the way UAE government has established legal framework that govern the implementation of public surveillance systems, some research gap still exists on what standardization measures are available in the country's public surveillance system. Research on the specific procedures and application for surveillance cameras control in the country remains scanty, despite the government's efforts in ensuring that high levels of public safety are guaranteed through surveillance systems. Research has shown that, the quality of surveillance systems is critical in the bid to curb crime using public surveillance system (Gill, 2006; Ratcliffe, \& Travis, 2008), and thus with the current lack of empirical evidence on standardization quality of surveillance cameras control system in UAE, there is need for up-to-date research aimed at assessing the standardization quality in the major complexes in the country's major cities. Moreover, very little empirical evidence is available on the type of surveillance system adopted in the UAE, as well as the guidelines that the government followed in establishing the public surveillance system, especially the location of the cameras. 
As such, much of the focus in this study seeks to find out the considerations that UAE's government has taken in the implementation of public surveillance systems, and compare with what the other countries have been doing. Moreover, the best surveillance camera systems that suit the country would also be a key focus in this study, alongside the technologies that can be leveraged to provide the best surveillance system in the country. Based on these gaps, this study seeks to explore the entire UAE's public surveillance system where the key considerations of the system design and its quality standards would be the utmost focus in this study.

\section{Findings}

The conceptual framework is a model developed in a research study based on the research gaps that shows the direction in a research study. With the key focus in this study being to explore the surveillance camera control systems in public agencies for offering the best guidance to United Arab Emirates in surveillance system, and setting the main principles to evaluate the system, in the same time maintain the privacy and fundamental rights for residents, figure 2.1 below illustrates the key areas of focus based on the research questions and objectives that guides the researcher in this study.

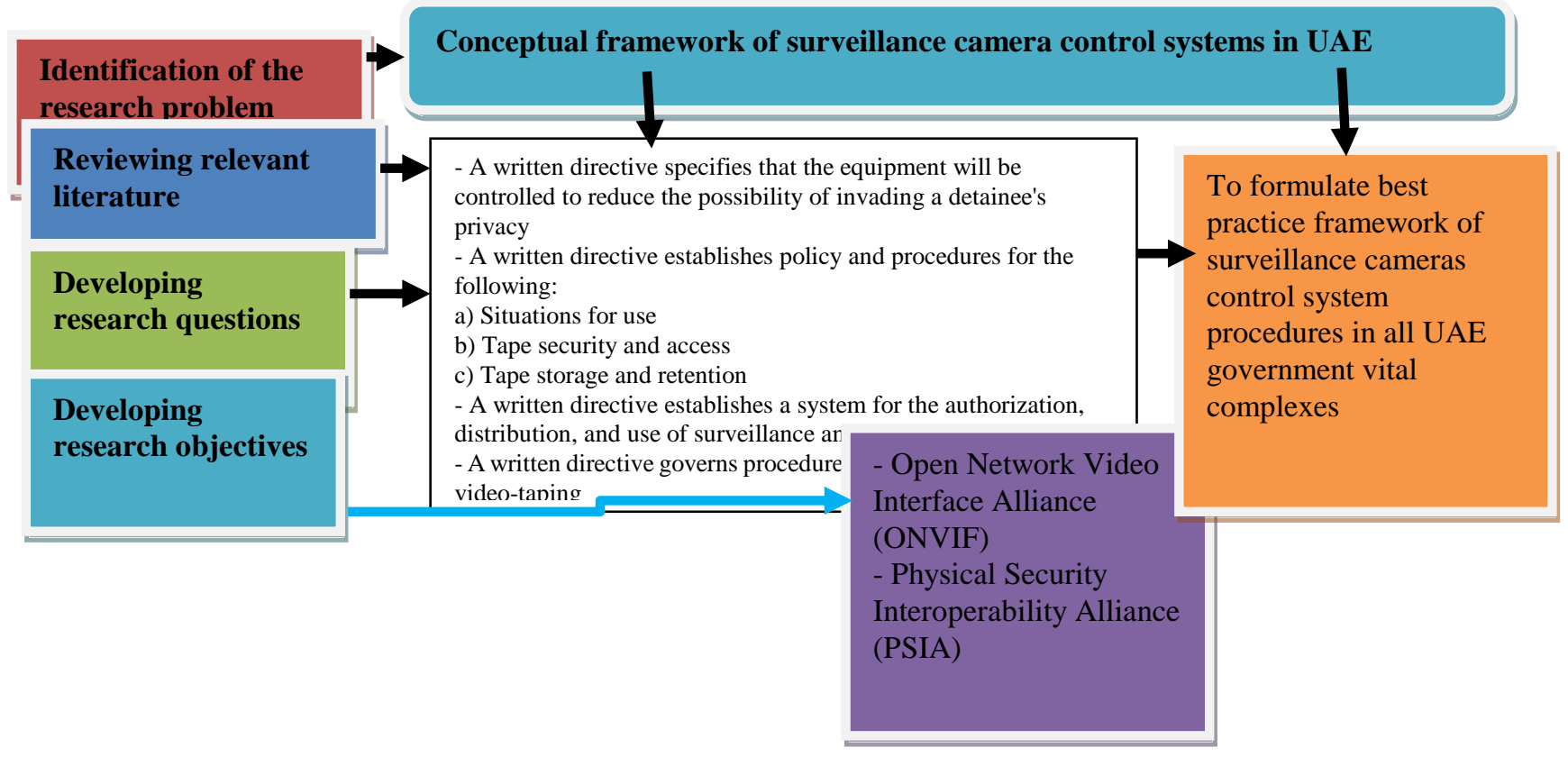

Figure 4: Conceptual Framework

\section{Conclusion}

As revealed in this review, public surveillance is a critical security component that contributes largely towards controlling of crime. However, researchers agree that the type of public surveillance system based on quality standards largely determine how effective such systems are. Moreover, researchers agree that not only the quality of the surveillance systems is an important consideration, but also the design of the system, how it is integrated in the environment, and the entire design, which altogether contributes significantly towards the success of the system and its ability to prevent crime in an area. While research shows that UAE has established legal framework for public surveillance systems, very little empirical research was available with regards to the quality of its system, the standardization procedures adopted, and the design the government has used in leveraging the public surveillance system, With research from across the world showing that public surveillance systems in some countries like US and UK have experienced significant decline in crime as a result of the availability of surveillance systems in major cities, the quality and design of the surveillance system was pointed out by researchers as an important consideration. This study, therefore seeks to bridge the research gap with regards to UAE's implementation of public surveillance system in terms of the quality of the systems, its design, and the standardization procedures adopted. In the next paper, a critical analysis of the methodology adopted in the study, where the data collection methods and procedures adopted, and the process of data analysis are presented. 


\section{References}

Adul-Hai, M. (2006). All roads in Abu-Dhabi are totally monitored by surveillance camera. Retrieved from: http://www.alittihad.ae/details.php?id=50317\&y=2006

Albayan. (2017. Installation of 73,375 surveillance camera for security control in Ras- Alkhaimah. Retrieved from: http://www.albayan.ae/across-the-uae/news-and-reports/2017-07-04-1.2994599

Al-Shanaq, A. (2015). Installation of security surveillance camera in 7500 traffic cars in Abu-Dhabi. Retrieved from: http://www.emaratalyoum.com/local-section/other/2015-06-07-1.791362

Alshenqeeti, H. (2014). Interviewing as a Data Collection Method: A Critical Review. English Linguistics Research Vol. 3, No. 1. 39:45.

Awang, Z. (2012). Research Methodology and Data Analysis (2nded.). Malaysia: MPWS Rich Publications.

Barr, R. \& Ken, P. (1990). Crime Placement, Displacement, and Deflection. Crime and Justice, 12, 277-318.

Brooks, D. J., (2003). Public street surveillance: A psychometric study on the perceived social Risk. Masters Degree in Science submitted at University of Sidney, Australia.

Bryman A. and Bell E. (2007).Business Research Strategies, Business Research Methods, (2nded.). New York: Oxford University Press.

Bryman, A. (2008). Social Research Methods (Third). New York: Oxford University Press.

Cahill, M., Samantha S. L., \& Downey P. M. (2010). Moving' Out: Crime Displacement and HUD's HOPE VI Initiative. Washington, D.C.: The Urban Institute.

Cameron, A., Kolodinski, E., May, H. \& Williams, N. (2007). Measuring the Effects of Video Surveillance on Crime in Los Angeles. CRB-08-007. Sacramento, CA: California Research Bureau.

Chileshe, N., Hosseini, M. R. and Jepson, J. (2016).Critical Barriers in Implementing Risk Assessment and Management Practices (Ramp) in the Iranian Construction Sector.Journal of Construction in Developing Countries, 2016 (Early View).

Chisholm, J. (2000). Benefit-Cost Analysis and Crime Prevention. Trends \& Issues in Crime and Criminal Justice. No. 147. Canberra, AU: Australian Institute of Criminology

Clarke, R.V. \& Mayhew, P. (1980). Designing out crime. London: Her Majesty Stationary Office (H.M.S.O).

Coleman, R. \&McCahill, M. (2010). Surveillance and crime. London: SAGE.

Cooper, D. and Schindler, P. (2011).Business Research Methods. New York: McGraw-Hill.

Cornish, D. B., \& R. C. (1987). Understanding Crime Displacement: An Application of Rational Choice Theory. Criminology 25(4), 933-47.

Creswell, J. (2014). Research design: Qualitative, quantitative and mixed methods approaches (4th ed.). Thousand Oaks, CA: SAGE Publications

Creswell, J. W., Hanson, W. E., Clark Plano, V. L., \& Morales, A. (2007). Qualitative Research Designs: Selection and Implementation. The Counseling Psychologist, 35(2), 236-264. https://doi.org/10.1177/0011000006287390

Creswell, W. J. (2014). Research Design Qualitative, Quantitative and Mixed Method Approaches(4th Ed.). Los Angeles:SAGE Publications.

Cumming, D., \& Johan, S. (2015). Cameras tracking shoppers: the economics of retail video surveillance. Eurasian Business Review, 5(2), 235-257.

Davis, F. D. (2004). Toward preprototype user acceptance testing of new information systems: Implications for software project management. IEEE Transactions on Engineering Management, 51 (1), 31-46.

DeLone, W.H. and McLean, E.R. (2003). The DeLone and McLean of information systems success: A ten-year update. Journal of Management Information Systems, 19(4), 9-30.

Denzin, N. K., \& Lincoln, Y. S. (2005). Handbook of Qualitative Research. Data Management and Analysis Methods (2nd ed.). Thousand Oaks: Sage Publications, Inc. https://doi.org/10.2307/2076551

Ditton, J. \& Short, E. (1999). "Yes, it works, no it doesn't: comparing the effects of open-street CCTV in two adjacent Scottish town centers". In Painter, K. \& Tilley, N.(eds). Surveillance of Public Space: CCTV, Street Lighting and Crime Prevention Crime Prevention, Studies Vol. 10 (pp. 201-223). Monsey: Criminal Justice Press.

Ditton, J. \& Short, E. (1999). "Yes, it works, no it doesn't: comparing the effects of open-street CCTV in two adjacent Scottish town centers". In Painter, K. \& Tilley, N.(eds). Surveillance of Public Space: CCTV, Street Lighting and Crime Prevention Crime Prevention, Studies Vol. 10 (pp. 201-223). Monsey: Criminal Justice Press. 
Ekblom, P., Armitage, R., Monchuk, L. \& Castell, B. (2013). Crime prevention through environmental design in the United Arabs Emirates: A suitable case for reorientation. Built Environment, 39(1), 92-113.

Flick, U., Kardorff, E. von, \& Steinke, I. (2004). A Companion to Qualitative Research. Thousand Oaks: SAGE Publications. https://doi.org/10.4135/9781412979306.n259

Flight, S., Van Heerwaarden, Y. \& Van Soomeren, P. (2003). "Does CCTV displace crime? An evaluation of the evidence and a case study from Amsterdam". In Gill, M. CCTV (pp. 93-108). Leicester: Perpetuity Press.

Frois, C. (2013). Peripheral vision: Politics, technology, and surveillance (Vol. 22). Berghahn Books.

Gill, M. \&Spriggs, A. (2005). Assessing the impact of CCTV. Home Office Research Study 292. www.homeoffice.gov.uk/rds/pdfs05/hors292.pdf. (Accessed April 25, 2018.).

Gill, M. (2006). CCTV: Is It Effective? In The Handbook of Security, (438-461). New York: Palgrave Macmillan.

Goold, B. J., (2002). Privacy rights and public spaces: CCTV and the problem of the 'unobservable observer'. Criminal Justice Ethics, 21(1), 21-27.

Grivna, M. \& Aw, T.C., Loney, T., Sharif, A.A. \& Thomsen, J. (2012). The legal framework and the initiatives for promoting safety in the United Arabs Emirates. International Journal of Inquiry Control and Safety Promotion, 19(3), 278-289.

Haggerty, K. D., \& Samaras, M. (2010). Surveillance and democracy. London: Routledge-Cavendish.

Haggerty, K.D., Wilson, D., \& Smith, G.J. (2011). Theorizing surveillance in crime control. Theoretical Criminology, 15(3), 231-237.

Haggerty, K.D. \& Gazso, A. (2005). Seeing beyond the ruins: surveillance as a response to terrorist threats. Canadian Journal of Sociology, 30(29), 169-187.

Han, J. H., Hawken, S., \& Williams, A. (2015). Smart CCTV and the Management of Urban Space.In Handbook of Research on Digital Media and Creative Technologies (pp. 430-447). IGI Global

Harris, L. R., \& Brown, G., T., L (2010). Mixing interview \& questionnaire methods.Practical Assessment, Research \& Evaluation, Vol 15, No 1. 